\title{
LA SOCIEDAD GIMNÁSTICA ESPAÑOLA Y LOS INICIOS DE LA EDUCACIÓN FÍSICA: UNA IDEA, UN PROYECTO, UNA REALIDAD (1887-1937)
}

\author{
Antonio Rivero Herraiz \\ Facultad de Ciencias de la Actividad Física y del Deporte (INEF) \\ Universidad Politécnica de Madrid \\ antonio.rivero@upm.es \\ http://doi.org/10.15366/citius2019.12.1.003 \\ Fecha de recepción: Marzo 2019 \\ Fecha de aceptación: Mayo 2019
}

\begin{abstract}
Resumen:
En este trabajo se realiza una investigación sobre de la Sociedad Gimnástica Española (SGE), fundada en Madrid en 1887. En él, tratamos de explicar la importancia que ésta tuvo en la implantación y desarrollo de la educación física y posteriormente del deporte en España. En un tiempo en que las prácticas físicas de la población se reducían a ciertos gimnasios aristocráticos y los deportes se restringían a los sectores más privilegiados de la sociedad, la Gimnástica irrumpió con un objetivo claro: llevar la práctica de la educación física y el deporte a todos los estratos de la población. La SGE entendió la educación física como un componente más del regeneracionismo que, como ideario político, ganaba presencia entre las clases medias urbanas. La SGE fue pionera en la promoción de las prácticas físicas en el Madrid de entre siglos, realizando una actividad de gran importancia hasta su desaparición en 1937. Sus archivos se destruyeron durante la Guerra Civil, de ahí la importancia de reconstruir su historia.
\end{abstract}

Palabras clave: Educación física, historia, gimnástica, gimnasia, deporte, sociedad.

Title: THE SOCIEDAD GIMNÁSTICA ESPAÑOLA AND THE BEGINNING OF PHYSICAL EDUCATION: AN IDEA, A PROJET, A REALTY (1887-1937)

\begin{abstract}
:
The aim of this article is to develop a research about Spanish Gymnastic Society (SGE, Sociedad Gimnástica Española), founded in 1887. We seek to explain the importance of this Society in the implantation and development of Physical Education and Sports in Spain. The RSGE rose with a clear objective: to bring the practice of Physical Education and sports to every social class of the population, during a period in which physical practices among people were just reduced to some aristocratic gyms and sports were reserved to the most privileged classes of society. SGE took Physical Education as an element of Regenerationism that, as a political idea, was earning presence among urban middle class. SGE was a pioneer in spreading physical practices in XIX-XX century's Madrid, bringing forward a very important activity, until it disappears in 1937. SGE's archives were destroyed during Civil War, a fact that stresses the importance of rebuilding its history.
\end{abstract}

Key words: Physical Education, History, Gymnastics, Sports, Society.

\section{Introducción}

Sería en la década de los ochenta del siglo XIX, cuando las primeras sociedades y clubes deportivos comenzaron a articularse en España (Torredabella, X; Olivera, J. y Bou, M., 2015). Al margen de las sociedades velocipédicas, la mayoría de estas asociaciones eran gimnasios o clubes sociales de rango aristocrático y restringido, junto a clubes hípicos, de lawn-tenis o deportes náuticos. Por eso podemos señalar a la Sociedad Gimnástica Española (SGE), nombrada Real Sociedad Gimnástica Española (RSGE) por el Rey Alfonso XIII en 1916 y 
fundada en Madrid el año 1887, como la sociedad decana en la promoción de la educación física y deportiva en España (Gran Vida, 1922; Sevilla, P. 1951), en cuanto a encarnar un proyecto moderno y global para el desarrollo de la cultura física entre las clases medias y populares, no importando la procedencia y el estatus social de sus afiliados, ya fueran hombres, mujeres o niños.

La Gimnástica- nombre por el que era conocida- fue una asociación pionera en la promoción de la educación física y los nuevos deportes entre los diferentes estratos de la población, desarrollando una tarea pedagógica y multifacética, practicando, además de la educación física: rugby, baloncesto, lucha, boxeo, montañismo, remo, pedestrismo, natación, excursionismo, atletismo y gimnasia (Salazar, 2000, p. 22-36).

\title{
2. La Sociedad Gimnástica Española
}

Para entender lo que significó la Sociedad Gimnástica Española en la España deportiva de su tiempo, basta citar el relato que la revista Gran Vida hacía de las bondades de ésta, en 1912, durante la celebración $25^{\circ}$ aniversario de su creación:

\begin{abstract}
«Cuatro jóvenes de arrestos, iniciativas, y, sobre todo de verdadera fe en el deporte, acordaron en una tertulia amistosa, el 2 de marzo de 1887, trabajar con todos sus afanes hasta ver funcionar una sociedad popular, democrática, que pusiera los deportes al alcance de todos los aficionados, que el estudiante, el empleado, el obrero pudieran combatir los vicios y embrutecimiento de la vida de esclavitud, de trabajo constante, con la expansión y equilibrio que proporciona al espíritu las emociones del deporte y lograr un desarrollo armónico de inteligencia y salud» (Polea, 1912, p.73).
\end{abstract}

Durante esos días, al cumplirse las bodas de plata de la institución, sin duda, fundamental en el desarrollo de la educación física y el deporte español, se organizaron en Madrid diversos actos conmemorativos. La prensa diaria y deportiva — sobre todo en Madridse hizo eco, por su relevancia, de estos acontecimientos.

Los cuatro jóvenes a los que se refería el artículo de Gran Vida eran: D. Narciso Masferrer Sala (presidente) y D. Emilio Coll Maignan (secretario), ambos nacidos en Madrid; Don Eduardo Charles (tesorero) francés de Tolouse y D. Emilio Fernández Monjardin (vocalcontador) del que no tenemos datos de su lugar de nacimiento.

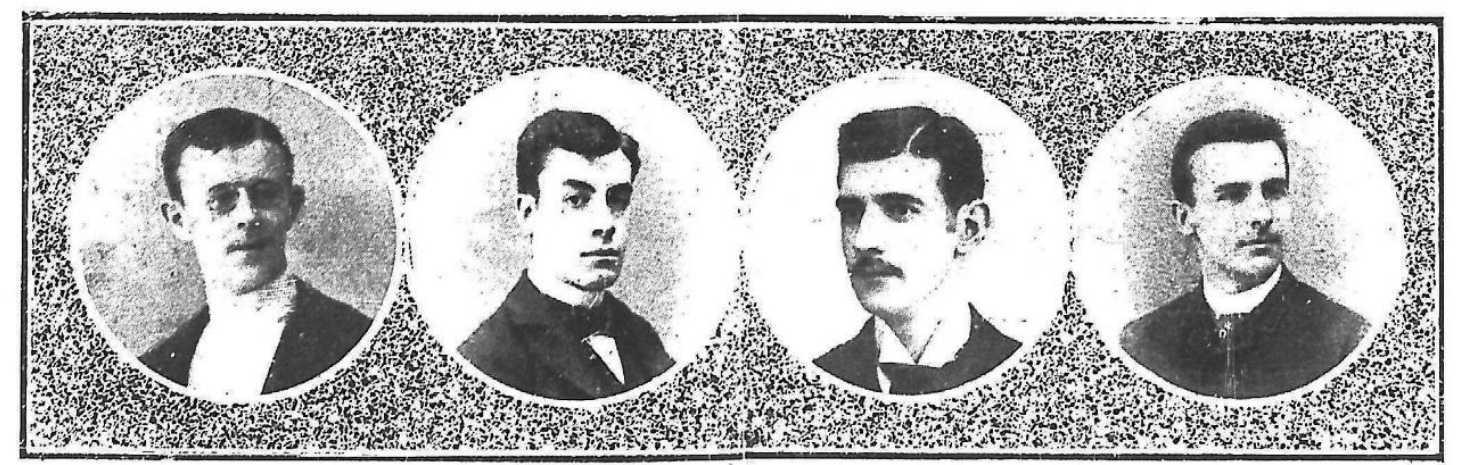

Sres. Masferrer, Moujardin, loll y Charles, fundadores.

Figura 1. Fundadores de la SGE. Gran Vida, (1912) n. ${ }^{\circ} 106$.

Es de justicia mencionar, aunque no como fundadores, a los profesores y prohombres del movimiento gimnástico de aquellos días: Don Mariano Marcos Ordax y Don Marcelo Sanz. $\mathrm{Su}$ apoyo fue muy importante. Don Mariano Marcos Ordax facilitó a los socios de la recién creada Gimnástica, la utilización de su gimnasio de la calle Prado n. ${ }^{\circ} 10$, por una cuota 
individual de 2,50 pesetas al mes, recibiendo además una clase diaria de gimnasia (Sevilla, 1951).

A pesar de la importancia que la Sociedad Gimnástica Española tuvo en la promoción de los deportes, su principal actividad fue la educación física, así lo expondría uno de sus más destacados presidentes, D. Pompeyo Sevilla:

«Porque hay que tener en cuenta que la S.G.E. fue la primera sociedad deportiva que se fundó en España, y su fundamento principal no fueron los deportes, como ha ocurrido con otras. No; fue la educación física; por eso jamás dejaron de darse clases de gimnasia para el mejoramiento de nuestra raza» (Sevilla, 1951, p.p.6-7).

En esta declaración de principios del Sr. Sevilla, vemos la clara impronta educativa del regeneracionismo que, durante mucho tiempo, inspiro a todas las sociedades gimnásticas y deportivas de la época.

\section{Los fundadores}

El origen de la Sociedad surgió de cuatro empleados en la sede madrileña de la Deutch de la Meurthe, empresa francesa de petróleos, y partió de la iniciativa del Sr. Coll, inspirándose al ver un ejemplar de la revista Le Gimnaste -órgano de las sociedades gimnásticas francesas-, que estaba sobre la mesa de su jefe (Sevilla. P, 1951).

Así el 2 de marzo de 1887, en Madrid, en el domicilio del Círculo de la Unión Mercantil se fundó la Sociedad Gimnástica Española, siendo elegidos para formar la junta directiva los cuatro jóvenes anteriormente mencionados. A ellos nos referiremos a continuación, pues consideramos de interés conocer las personalidades de estos cuatro pioneros del asociacionismo deportivo español.

D. Narciso Masferrer Sala (Madrid, 1868- Barcelona, 1941). Narciso Masferrer nació y se crio en Madrid, donde también contrajo matrimonio. Cuando fue elegido presidente y tomó las riendas de la sociedad apenas tenía veinte años. Impulsado por su interés en promover los deportes fue, junto a Emilio Coll, uno de los primeros periodistas deportivos en España. Por motivos profesionales se asentó en Barcelona, allí continuó con su labor como promotor del deporte. Doce años después de fundar la Sociedad Gimnástica Española, fue fundador del F.C. Barcelona en 1899. Para darnos cuenta de su actividad en la Ciudad Condal podemos citar que fundó las revistas: Los Deportes, Vida Deportiva, El Mundo Deportivo y Vida Moderna. También colaboró en El liberal y La Vanguardia. Fue pionero en el impulso de la organización de unos JJ.OO. en Barcelona (Torrebadella-Flix, 2015) y propuso la construcción del estadio de Montjuich pensando en la organización de éstos en Barcelona. Consiguió con sus campañas escritas la creación del Club de Natación, de la Federación Catalana de Atletismo, e impulso la creación de la Federación Española de Fútbol, también inició y presidió el Sindicato de Periodistas Deportivos (Sevilla, 1951).

Masferrer, también fue el organizador de la primera carrera de camiones entre Barcelona y Madrid, donde fue recibida por el rey Alfonso XIII. Desde su casa de la calle Balmes en Barcelona organizó, junto a su familia, el I Salón Internacional del Automóvil, continuando en la misma durante los años siguientes hasta la guerra civil. Finalizada la guerra, el Comité Olímpico Español- Consejo Nacional de Deportes, le nombró consejero y por quinta vez fue presidente de la Unión Velocipédica Española (Mora, 1970). Falleció en Barcelona en 1941 a los setenta y tres años. Su figura humana y su actividad fueron de vital importancia en los inicios del deporte español.

D. Emilio Coll Maignan (Madrid, 1968-1941). Fundador, secretario y eje de la SGE, además de trabajar junto a sus tres compañeros en los duros años del comienzo, estuvo durante 
toda su vida pendiente de la marcha de la Sociedad. Decía de sí mismo «yo soy el bombero de la Sociedad», pues siempre se recurría a él cuando había algún asunto de gravedad que solucionar. De familia acomodada y de profesión sus negocios comerciales, al igual que Masferrer, colaboró desinteresadamente como periodista en Los Deportes, Mundo Deportivo y Stadium de Barcelona y en Madrid para España Sportiva, Boletín de la Unión Velocipédica Española - de la que fue presidente de su Comité- y El País. También fue tesorero de la Federación Gimnástica Española (Sevilla, 1951).

D. Eduardo Charles (Tolouse, ...-1919). Fue elegido como tesorero. Persona formal y bondadoso colaborador. Debido a compromisos profesionales tenía que ausentarse con frecuencia de Madrid, por lo que no podía dedicar el tiempo que deseaba a la Sociedad. Abandonó España enfermo en 1917, muriendo 1919 en Tolouse, su ciudad natal (Sevilla, 1951).

Por último, citaremos a D. Emilio Monjardín, vocal contador de la primera junta directiva. Se sabe de él que murió joven, a los 26 años, y desconocemos con seguridad su lugar y fecha de nacimiento. Se le recuerda como una persona vehemente que solía discrepar del criterio general pero que siempre aceptaba y cumplía con los acuerdos tomados. (Sevilla. 1951).

\section{Los comienzos y la primera ley de Educación Física}

Aunque los comienzos no fueron fáciles, la actividad no cesó desde el primer día. Los impulsores del proyecto se encontraron con una indiferencia generalizada y promesas incumplidas por parte de las instituciones de las que se podía esperar alguna ayuda. Hay que decir que el 9 de marzo de 1883, se había aprobado en las Cortes la primera Ley de Educación Física en España, pero hasta 1886 no se publicó su reglamento. Este retraso en su aprobación fue un ejemplo de los muchos problemas que vendrían después. Lo mismo ocurriría con la construcción de gimnasios en institutos y colegios públicos que se demoraría durante mucho tiempo. Las clases en la recién creada Escuela Central de Gimnasia comenzaron el 1 de octubre de 1887. Su director fue el Dr. Mariano Ordax, le sucedió el Dr. San Martín. La institución funcionó solamente cuatro años, en 1892 una reestructuración presupuestaria retiró las 100.000 pesetas anuales que la Escuela Central tenía como subvención, por lo cual se cerró. Durante estos cuatro años se titularon en ella 16 profesoras y 71 profesores. El incumplimiento de esta ley desde el principio por la misma administración, la falta de recursos y el desinterés general acabó con esta oportunidad de instaurar la educación física dentro del sistema educativo español y de mejorar los hábitos higiénicos de los niños y jóvenes (Rivero, 2003).

Estos inconvenientes, en el desarrollo de la Educación Física nacional, no echaron para atrás a La Gimnástica en su iniciativa de dar vida a su proyecto, pionero en España. Como ya hemos mencionado la ayuda del catedrático Sr. Ordax — director de la Escuela Central de Gimnasia durante su efímera existencia-, que puso a disposición de la Sociedad su gimnasio y sus consejos, fue determinante en estos principios. Hay que resaltar que por entonces solo hacían gimnasia algunos enfermos - por prescripción médica - y personas de ideas avanzadas y cierto poder económico.

La actividad que la SGE desarrolló desde un principio fue imparable. En 1888 fundó su primera publicación, El Gimnasta. El 1 de marzo de 1898, Narciso Masferrer y Sala, desde el periódico Los Deportes, publicó un artículo pidiendo a todos los interesados en la gimnasia formar una asociación o incluso una federación gimnastica (Tello, J. 1998). El llamamiento tuvo éxito y en el mes de junio se constituyó la Federación Gimnástica Española con domicilio social en la calle Prado, n. ${ }^{\circ} 10$ de Madrid, era el gimnasio del Sr. Marcos Ordaz y lugar de prácticas de la Gimnástica. La publicación barcelonesa Los Deportes sería su órgano de difusión oficial y el jefe de gobierno, José Canalejas, presidente de honor. Hemos de señalar que los cuatro fundadores de la SGE: Masferrer, Coll, Charles y Monjardín, formaron parte de la junta directiva de la Federación (Los Deportes, 1898). El 15 de julio se publicó en la misma revista la 
lista de delegados provinciales en toda España (Los Deportes, 1898). La Federación Gimnástica Española ya era un hecho.

\section{Ideario y emblema}

El escudo de La Gimnástica, que debía representar los valores de la misma, estaba compuesto por un anagrama formado con la letra «F» cuatro veces. Eran las iniciales de franco, fuerte, fresco y firme, cuatro palabras congruentes con el ideario regeneracionista que tanto influyó a los pioneros de la educación física y el deporte español de finales del siglo XIX y principios del XX (Rivero y Sánchez, 2011).

Este escudo diseñado en 1988 fue sufriendo modificaciones: el 14 de junio de 1893 se aprobó sustituir a las cuatro efes — provenientes del profesor alemán Jahn — por el lema: «Sé fuerte y serás libre». El 14 de junio de 1905 se aprobó el escudo definitivo, diseñado por el socio D. Rafael Carcedo, en él seguían apareciendo las cuatro efes. En la junta general de 3 de noviembre de 1931, se aprobó agregarle los colores blanco y negro de la sociedad (Sevilla, 1951).

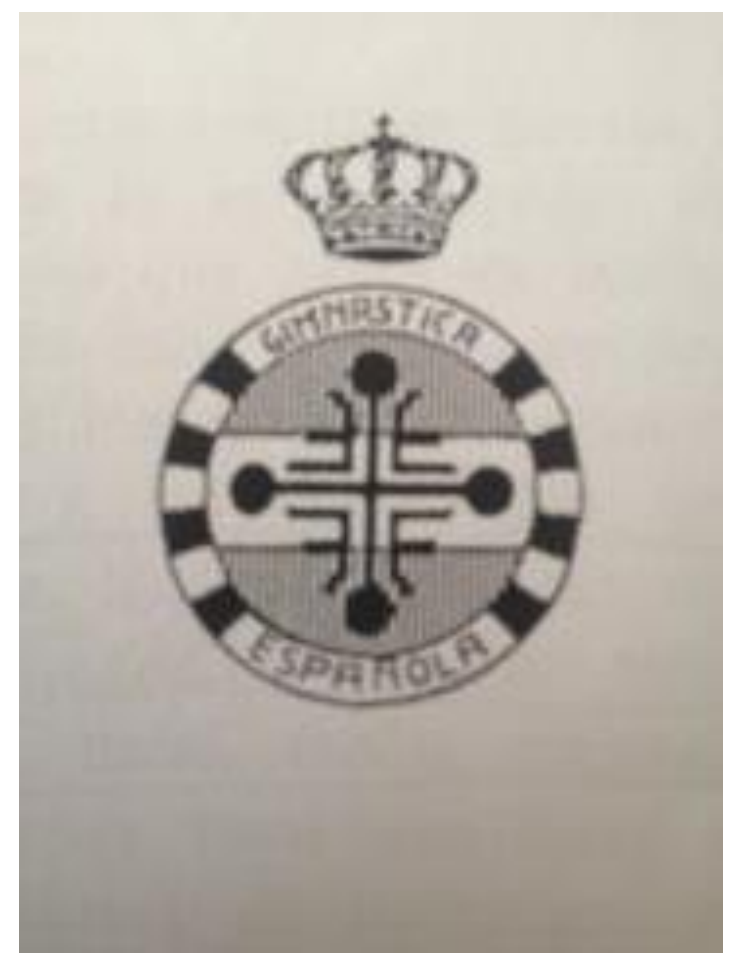

Figura 2. Escudo de la RSGE, Sevilla. P. (1951)

Importantes personajes de la política y de la Ciencia fueron socios de número de $L a$ Veterana, nombre con el que también se conocía a la sociedad pionera del deporte español. Entre ellos destacar: D. José de Canalejas, Presidente del Gobierno; D. Manuel Becerra, Ministro de fomento y artífice de la primera ley de Educación Física en España, aprobada en Cortes en 1983; D. José Franco Rodríguez Ministro de Gracia y Justicia, etc.

Fueron presidentes de la sociedad hombres de Ciencia, como el catedrático de la Facultad de Medicina D. Enrique Isla, y el sabio y cirujano D. Alejandro San Martín, que, dado su prestigio, hizo que la Sociedad ganara mucho reconocimiento. En los últimos tiempos también fue socio el mundialmente conocido D. Ramón Castroviejo. Sin subvenciones ni mecenas, la cuota de tres pesetas mensuales de los socios era la que hacia subsistir a la sociedad. 
En 1901 su presidente el catedrático Eduardo Reyes, consiguió que el Estado la declarase sociedad benéfica, evitando así el impuesto que, hasta entonces, la sociedad pagaba como si fuera un casino o circulo de recreo (Sevilla, 1951).

\section{«a Cueva» y las posteriores instalaciones.}

Por fin, la sociedad encontró un lugar para asentarse, fue en el número 5 de la calle Marqués de Leganés, cercana a la actual Gran Vía, por entonces todavía inexistente. El lugar, dadas sus característica y ubicación, fue denominado como «La Cueva». Así se describía, por la prensa deportiva, la actividad allí desarrollada:

«La famosa cueva de la calle Marqués de Leganés fue la cuna de la educación física y el deporte español. Alli se reunían las juventudes estudiosas, que al diseminarse por España durante las vacaciones eran propagandistas entusiastas de la educación física» (Gran Vida, 1922, p. 140141).

Y así nos la describe D. Pompeyo Sevilla, socio y posterior presidente de la R.S.G.E.:

«Se le llamó La Cueva, porque así se denominó antiguamente esta calle y ser un semisótano, cuyas ventanas asomaban al ras de la acera de la calle. Los interiores daban a un gran patio con árboles, y otras a dos más pequeños. La nave de gimnasia para adultos era de unos ocho metros de anchura por veinticuatro de larga, y la de infantiles a donde iban algunos que hoy son médicos, tendría unos ocho por ocho metros. Su altura era como la de un piso corriente, de unos tres metros y medio, o sea de poca cubicación para el destino que se le daba. Los niños siempre fueron los mejor atendidos, pues siempre tenían su profesor titular, y solo se les permitía hacer lo que éste ordenaba hasta la edad de quince o dieciséis años» (Sevilla, 1951, p.21).

En La Cueva tuvo lugar la evolución y desarrollo de la gimnasia y se sentaron muchas de las bases de la futura educación física española, que luego se impartiría en centros escolares. Los hombres fuertes, pero de músculo corto, con pulmones y corazón deficitario, se fueron transformando - gracias a la nueva gimnasia - en auténticos y verdaderos atletas (Sevilla, 1951). Ya se habían celebrado, con gran éxito, las conmemoraciones de su XXV aniversario, cuando en su inquietud por crecer y extender los hábitos del ejercicio físico, La Gimnástica consiguió con mucho esfuerzo, en 1913, hacerse con su primer campo de deportes al final de la calle Rodríguez Sampedro, casi en la calle Princesa (Gran Vida, 1913). La Gimnástica se ganó a los deportistas de la barriada de Argüelles, al establecer allí, en los desmontes de la calle Princesa, hacia Moncloa, su campo de deportes. Los campos se construyeron en un solar de la condesa de Águila Real, con la que se acordó un alquiler soportable para la sociedad (Salazar, 2000). El vallado de este campo de Deportes entre las actuales calles de Rodríguez San Pedro, Gaztambide, Menéndez Valdés e Hilarión Eslava — que también fue el primer campo de deportes vallado de Madrid- motivó un gran crecimiento de asociados, pasando de los doscientos de los primeros años a setecientos. El nuevo campo se inauguró con diversas pruebas atléticas, así se refería a este hecho la prensa de la época:

«Además del festival de inauguración, ya se han jugado en el campo dos importantes partidos de fútbol; uno con el Internacional y otro con el Benfica de Lisboa; en todos estos concursos selecto público presenció las pruebas, cundiendo las alabanzas para la Sociedad por el impulso que en pro de la educación física viene realizando desde hace tiempo» (Gran Vida, 1913, p.120).

Se crearon las secciones de todos los deportes con concursos mensuales de todas ellas: esgrima, lucha, boxeo, atletismo, montaña, náutica, fútbol y ciclismo. También se organizaban conferencias y festivales artísticos (Sevilla, P. 1951).

En 1922, la directiva en una valiente decisión consiguió salir de La Cueva de Marqués de Leganés y abrir un nuevo gimnasio en la Calle Barbieri y, poco después, un nuevo campo de deportes en las calles Diego de León y Torrijos, cuyas gradas podrían albergar hasta 15.000 
espectadores (Gran Vida, 1922).

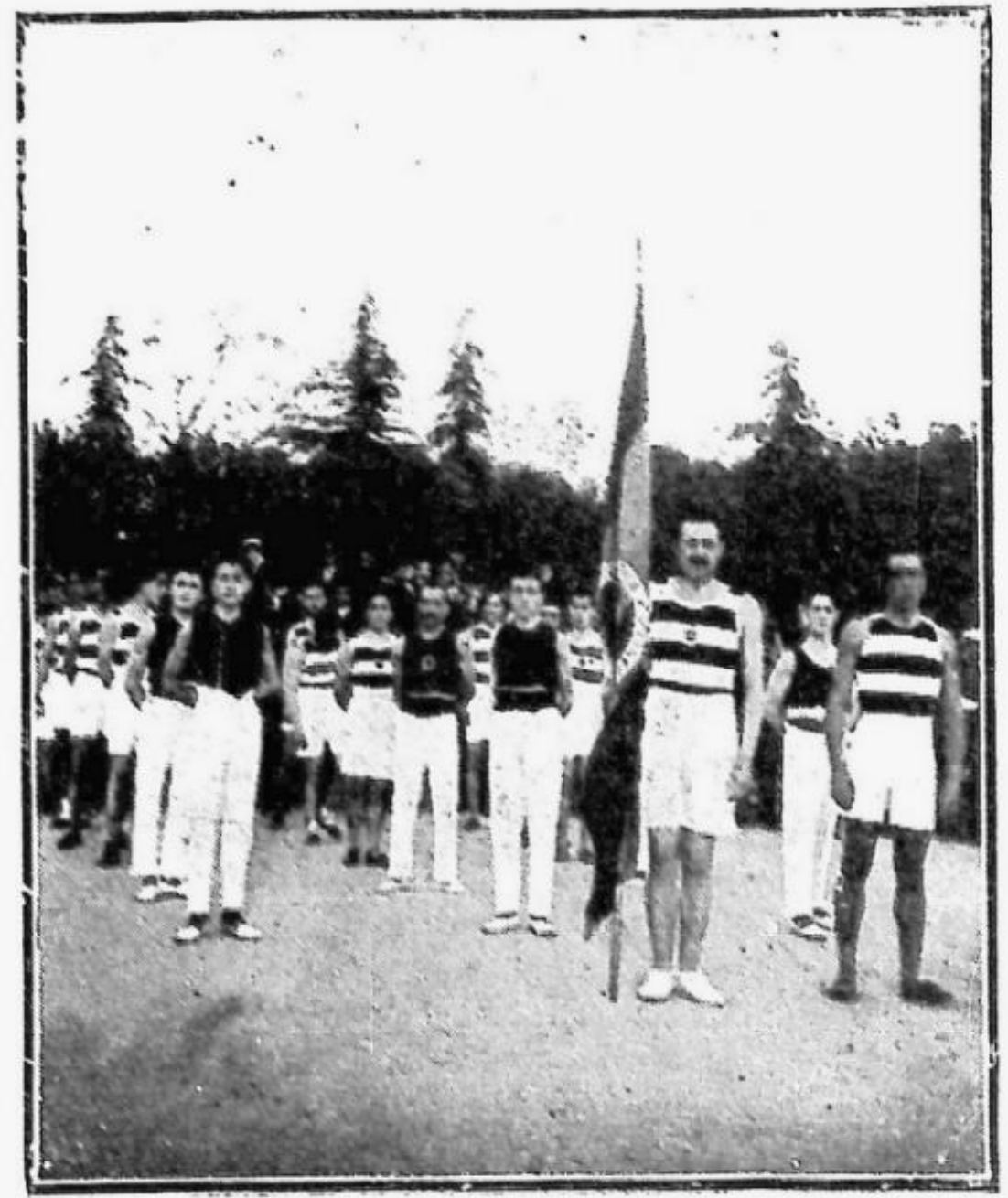

Figura 3. Atletas de la R.S.G.E. Gran Vida (1918), n. ${ }^{\circ} 178$.

Así, el 6 de marzo de 1922, se inauguró el nuevo gimnasio situado en la esquina de la calle Barbieri, 20, con Libertad, 27 (en este lugar posteriormente se construyó el actual mercado de San Antón). La decisión se tomó en Junta General durante 1920, cuando se acordó realizar un ahorro del $20 \%$ de cuotas. Se pasó de un alquiler de 175 al otro de 1000 pesetas al mes. Con 12.000 pesetas, ahorradas se decidió buscar un nuevo domicilio y acometer los primeros gastos. El nuevo local sería el mejor gimnasio de Madrid: 504 metros cuadrados, 12 metros de altura, luz cenital, ventilación lateral a ambos lados, lavabos individuales y vestuarios con duchas para un centenar de usuarios. En este mismo mes se produjeron 671 nuevos socios. (Sevilla, 1951). Esta instalación fue decisiva para el desarrollo de La Gimnástica como entidad y la promoción de la educación física entre niños, jóvenes y adultos madrileños.

El 4 de junio, del mismo año, se inauguró con un partido entre el Real Madrid y $L a$ Gimnástica el nuevo campo de deportes, situado entre las calles Diego de León, Torrijos, Maldonado y General Porlier (en este lugar, se encuentra actualmente el Hospital de La Princesa). En 1920, cuando ya se sabía de la próxima apertura de las nuevas instalaciones y gracias al aumento del número de socios, la recaudación fue de 27.566 pesetas y aumentó en 1921 a 52.093. Estas nuevas instalaciones fueron utilizadas por la SGE hasta su disolución. 


\section{Algunos hitos importantes en la historia de la Sociedad Gimnástica Española.}

Desde sus comienzos en 1887, la Sociedad Gimnástica Española no cesó en su febril actividad hasta su desaparición en 1937, durante la Guerra Civil.

Una vez lograda la creación de la Federación Gimnástica Española, en 1898, la actividad de la sociedad nunca dejó de sorprender con la organización de actividades físicas de todo tipo y dedicada la promoción de importantes eventos deportivos. A continuación, y realizando un estudio de las noticias que iban a apareciendo en las diferentes publicaciones deportivas de la época, citaremos, sumando a las ya citadas, algunos de los logros de la SGE con el objetivo de dar una dimensión real de lo que esta significó en el desarrollo de la educación física y los primeros deportes, primero en Madrid y luego por extensión en toda España, gracias a la posterior influencia de sus socios.

En el año 1891 se creó la ficha antropométrica, herramienta de gran importancia para controlar el desarrollo físico, sobre todo, de los niños y adolescentes. Un gran avance que da idea de la preocupación que los directivos tenían por la eficiencia de sus métodos de entrenamiento y sus resultados.

Una vez asentada la educación física «vinieron los deportes al aire libre y estos fueron los que dieron a conocer lo que era la Sociedad» (Sevilla, 1951, p.24). Cuando un socio llevaba unos meses haciendo gimnasia y su condición física se consideraba como buena, los responsables de la gimnástica le convencían para hacer el deporte más acorde a sus condiciones y habilidades, a los pocos meses eran destacados deportistas, dada su gran preparación física (Sevilla, 1951).

En 1893 se crearon las secciones de náutica y remo, realizando sus primeras prácticas en el estanque del parque del Retiro, donde organizaron numerosas competiciones.

En 1907, siendo presidente D. Joaquín del Moral, uno de los equipos de fútbol que se acababan de formar en Madrid, el Moncloa, pidió su ingreso en masa en la SGE, para así crear una potente sección de fútbol. Dada la reciente adquisición de su nuevo campo de deportes en los aledaños de la calle Princesa, el nuevo equipo se ganó a los aficionados del barrio de Argüelles. En los años 1911 y 1912 ganó la Copa de Madrid y en 1914 la primera liga regional. Su mayor éxito fue disputar la final de la Copa de España en 1912, perdiendo 2-0 frente al Fútbol Club Barcelona. (Salazar, 2000). Sus jugadores eran destacados practicantes de otros deportes, algunos de ellos campeones de España en diferentes pruebas atléticas.

Siguiendo el orden cronológico, hay que mencionar el gran protagonismo de la sociedad en la Semana Deportiva organizada el año 1908 en el campo de Exposiciones del Retiro, lo que le valió una condecoración por parte del Ayuntamiento de Madrid (Sevilla,1951). 


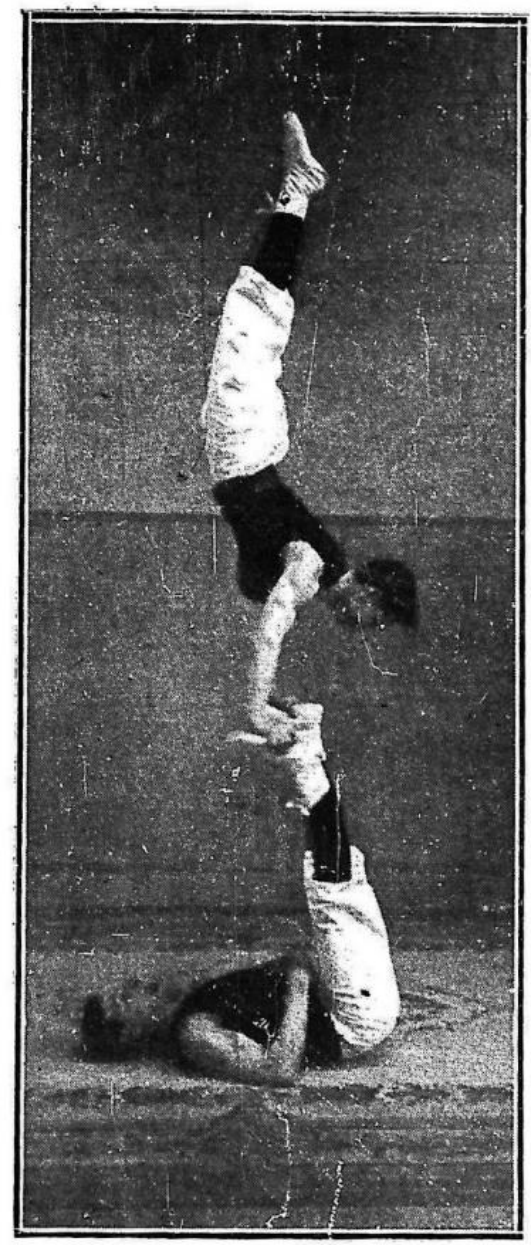

-

Figura 4. Srs. Serrano y Población. Gran Vida, (1912), n. ${ }^{\circ} 106$

En cuanto a su espíritu innovador en la organización de nuevos eventos atléticos debemos mencionar la organización en 1910 de la prueba de los $10 \mathrm{Km}$, en carretera (Gran Vida, 1910), que posteriormente se completarían con la disputa de numerosas ediciones de la Legua Española, distancia propia de la toponímica española y que se disputaba en el paseo de Recoletos, utilizando como vestuario las dependencias del conocido Café Gijón (Heraldo Deportivo, 1926). También este espíritu innovador de la Gimnástica consiguió traer a Madrid al luchador japonés Raku, «este hombre, a principios de siglo, fue el que trajo a España la lucha japonesa, o sea el jiu-jitsu» (Sevilla, 1951, p. 28).

En 1912, se celebró con gran éxito el XXV aniversario de la creación de la Sociedad. Se realizaron en el Circo Price exhibiciones gimnásticas y de esgrima, asaltos de boxeo y lucha greco-romana. Desde la Plaza de Oriente partió una prueba ciclista. En el estanque del Retiro se realizaron regatas para embarcaciones de cuatro remeros con timonel y una exhibición de natación. También hubo pruebas ciclistas en el velódromo de Ciudad Lineal. El mismo día, por la tarde, se celebraron las competiciones de atletismo. También las celebraciones se llevaron a la Sierra de Guadarrama, donde hubo carrera de «skis». El éxito fue total y la asistencia de autoridades dio la máxima importancia al evento que se reflejó con gran énfasis en la prensa madrileña y nacional, destacando las alabanzas a la Sociedad del Mundo Deportivo de Barcelona (Polea, 1912).

En 1914 se organizaron por el Athletic Club los llamados Juegos Olímpicos Madrileños, considerada como la primera competición multideportiva celebrada en España (Gran Vida, 1914) y cuyo nombre tuvo que dejar de utilizarse, por razones evidentes. Los deportistas de la 
Sociedad Gimnástica Española ganaron 17 de las 21 pruebas celebradas (Gran Vida, 1922). En esta competición, miembros de su sección de atletismo, usaron por primera vez zapatillas de clavos en Madrid (Sevilla, 1951). Durante estos años se organizaron campeonatos de halterofilia y de gimnasia en el circo Price, etc.

En 1916 y debido a sus méritos, el rey Alfonso XIII, gran amante de los deportes, concedió a La Gimnástica el título de «Real» que ésta llevaría con orgullo, hasta el triunfo de la República en 1931 (Rivero, 2012).

En su haber también está la organización en sus modestas pero concurridas instalaciones de los primeros campeonatos de boxeo aficionado cebrados en Madrid (Heraldo Deportivo, 1919), éstas continuarían a lo largo de los años.

Entre 1916 y 1920 el Ayuntamiento de Madrid, por primera vez, concedió a la RSGE una subvención de mil pesetas anuales (Sevilla, 1951).

En 1921, conocida la próxima inauguración del nuevo gimnasio en la calle Barbieri la R.S.G.E. llegó a los 2.000 socios, de los cuales 170 pertenecían a la sección de boxeo, 400 a la de atletismo y 350 al de fútbol y se impartían, para todos, clases de gimnasia sueca y combinada (Gran Vida, 1922). Ese mismo año el 18 de septiembre, se celebró en los campos de la calle Princesa la primera exhibición en España de atletismo femenino (Sevilla. 1951).

En 1922, como ya hemos explicado anteriormente, comenzaron las actividades en el nuevo gimnasio de Barbieri 1921 y el nuevo campo de deportes en las calles Diego de León y Torrijos, cuyas gradas podrían albergar hasta 15.000 espectadores (Gran Vida, 1922).

En 1925 y dado el carácter científico que, como garantes de una buena educación física, siempre tuvieron los directivos de la sociedad se puso en marcha la ficha médica para todos los socios de la RSGE

En 1927, la Educación Física seguía siendo la principal preocupación de los directivos de la RSGE y, por ello, trajeron a Madrid para impartir clases en sus instalaciones al famoso profesor húngaro Andrés Schwarz, representante máximo de la escuela gimnástica centroeuropea de la época, este hecho fue muy resaltado por la prensa deportiva madrileña (Gran Vida, 1927).

El fútbol, deporte en alza, se fue profesionalizando en España. El éxito del equipo nacional en los JJ.OO. de Amberes consiguiendo la medalla de plata catapultó su popularidad. Figuras como Ricardo Zamora entraron en la era del profesionalismo, ya existente en otros países (Rivero, 2003). Tras arduas disputas entre partidarios del amateurismo y del profesionalismo, éste último se oficializó en 1926. La Real Sociedad Gimnástica Española decidió mantener el estatus amateur en todas sus secciones deportivas. Tras un par de años problemáticos, la sección de fútbol se suprimió en 1928. 


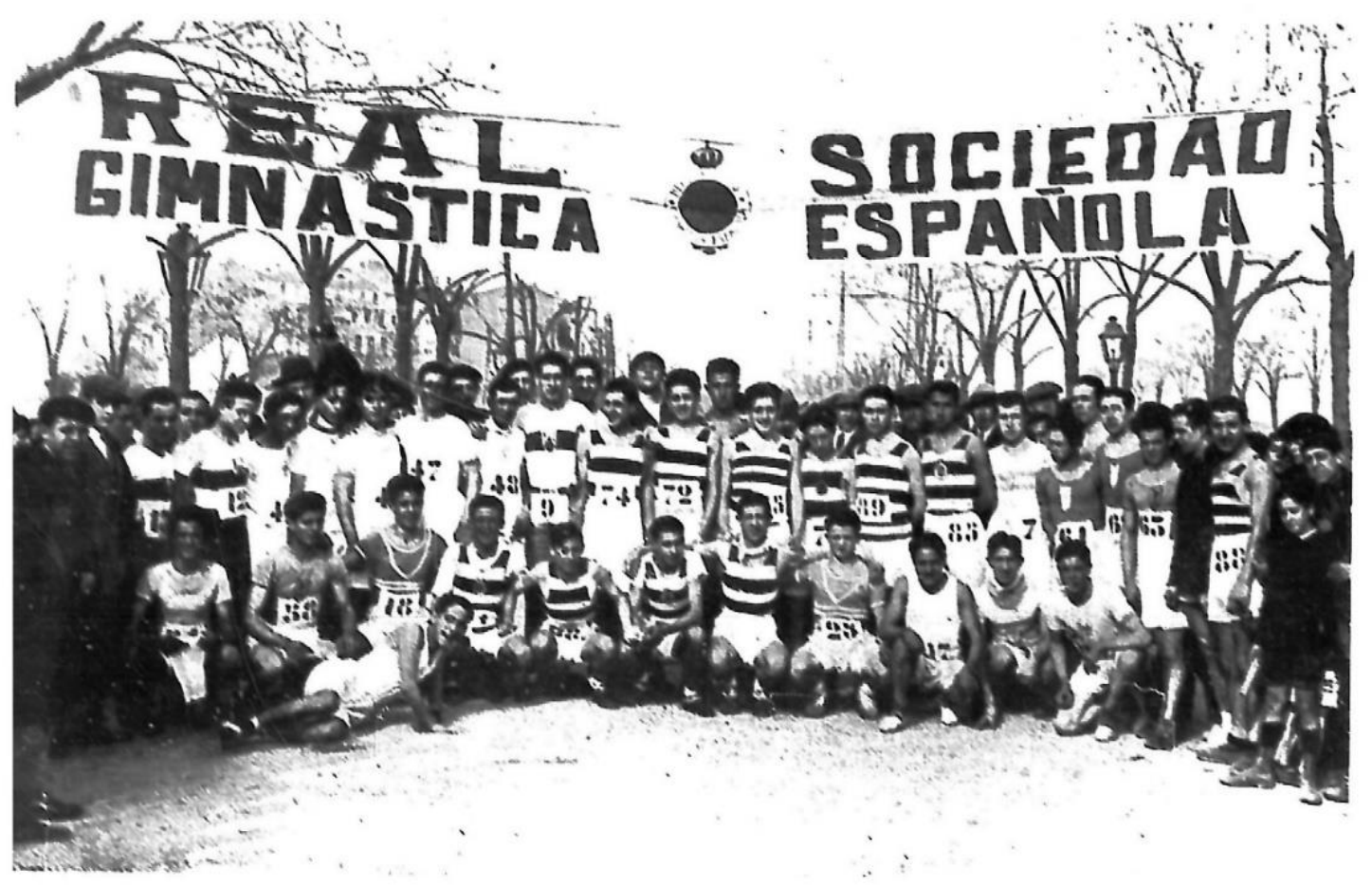

Figura 5. Copa Caso, torneo social organizado por la RSGE, Heraldo Deportivo (1926), n. ${ }^{\circ} 387$

En 1929 la R.S.G.E organizó con gran éxito de participación y de público la I Semana Gimnástica, que seguiría realizándose con gran éxito hasta el estallido la Guerra Civil en 1936. Hay que destacar la gran participación femenina en todas las ediciones, lo cual demuestra el espíritu innovador y progresista de los dirigentes de la RSGE. Este mismo año se decidió que el fútbol solo se practicaría en el ámbito aficionado.

En 1931, con la llegada de la II República, la Real Sociedad Gimnástica Española, obviamente, tiene que retomar su antiguo nombre de Sociedad Gimnástica Española.

En 1932 asistió a la celebración de la Semana Gimnástica, una delegación de los Sokols, sociedad gimnástica y patriótica checa de gran prestigio en toda Europa (Esparza, 2012). A su acto principal, con discurso de su presidente Sr. Reyes, no asistieron las autoridades municipales, debido posiblemente a desacuerdos con los gobernantes del consistorio.

Las semanas gimnásticas se fueron sucediendo hasta el comienzo de la Guerra Civil en 1936.

Durante la Guerra Civil un incendio en la calle Barbieri destruyo la casa de al lado del gimnasio y parte de éste se incendió, perdiéndose los archivos del club.

En 1937, la Sociedad Gimnástica Española — ya sin el título de Real desde 1931 - dejó de existir. (Sevilla. 1951).

Una vez terminada la guerra, las formas de entender y organizar la actividad física y el deporte de la SGE no encajaban en las estructuras deportivas del nuevo régimen, por lo que nuestra veterana asociación, no pudo reconstruirse de nuevo. Sin duda, muchos de los miembros supervivientes a la contienda siguieron ligados al deporte y fueron parte de la organización deportiva de la postguerra. 
La Sociedad Gimnástica Española fue un ejemplo de organización, de solidaridad y de utilización de la actividad físico-deportiva, como medio de modernización y transformación social y cultural de la juventud de su tiempo. Gracias a su impulso muchos madrileños pudieron llevar a cabo sus anhelos deportivos, dejando sembrada la semilla de la cultura física y deportiva entre niños, jóvenes y adultos (Rivero, 2012).

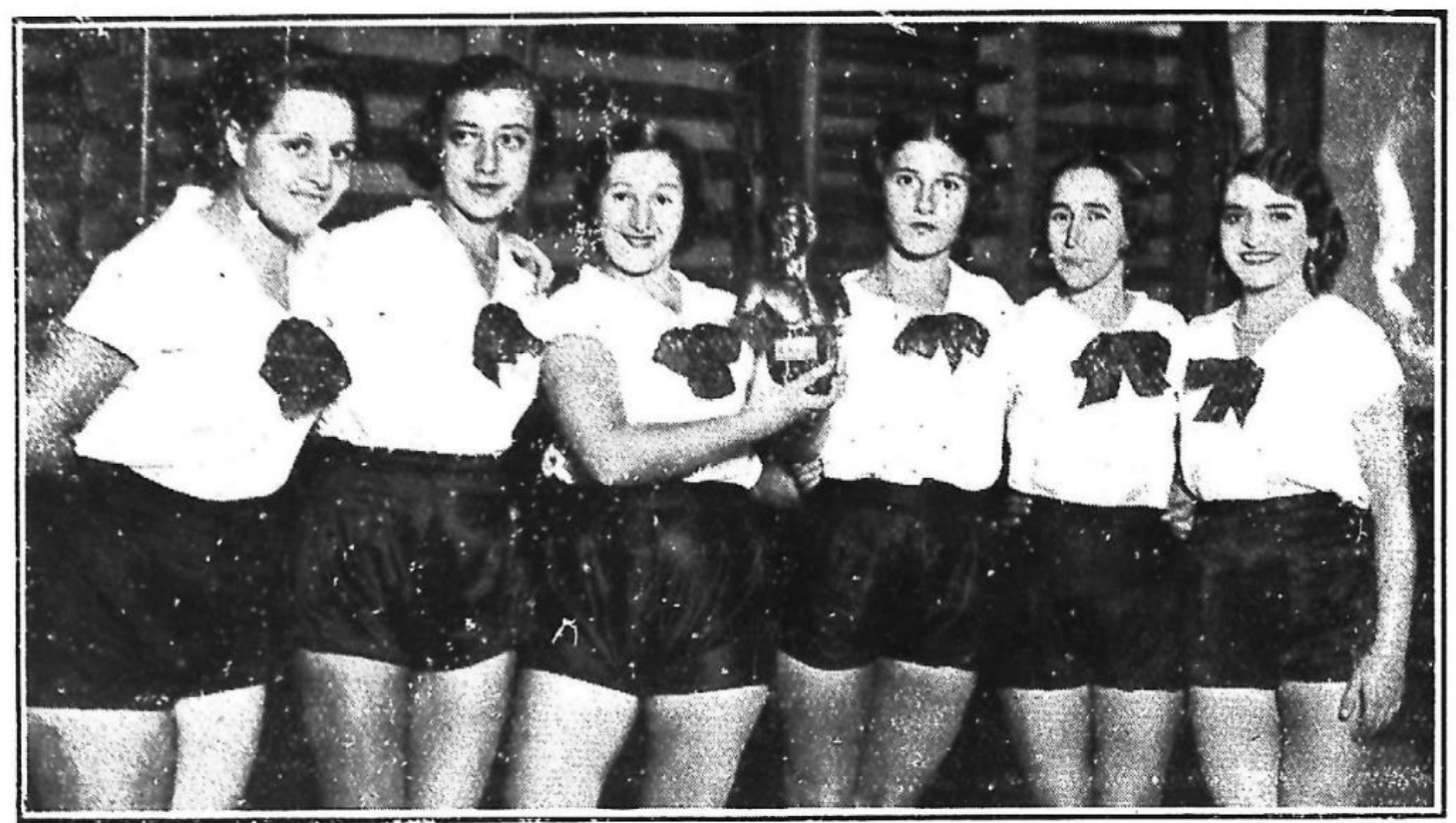

Figura 6. III Semana Gran Semana Gimnástica. Equipo que tomó parte en el concurso de mazas. Gran Vida, (1932) n. ${ }^{\circ} 353$

\section{Referencias bibliográficas}

- A.A. (1914). Juegos olímpicos en Madrid. Gran Vida, $n .^{\circ} 131,105-109$.

- Aníbal, K., (1910) Deportes atléticos en Madrid, Gran Vida, n. ${ }^{\circ}$ 83,116.

- Atletismo, (1926), Heraldo deportivo, $n .^{\circ} 387,67$. https://doi.org/10.1002/andp.19263870106

- El famoso húngaro Schwarz, profesor de la Real Sociedad Gimnástica, (1927), Gran Vida, $n .^{o} 293,140$.

- Esparza, D. (2012). Miroslav Tyrs y el sokol. RICYDE, 8 (27), 103-105.

- El campo de deportes de la Sociedad Gimnástica española, (1913), Gran Vida, n. ${ }^{\circ} 119,120$.

- La benemérita Gimnástica Española. (1922). Gran Vida, n. ${ }^{\circ} 227,140-141$.

- La III Gran semana gimnástica. (1932). Gran Vida, n. ${ }^{\circ}$ 353, 374.

- La «legua española» a pie. (1926). Heraldo deportivo, n. ${ }^{\circ} 414,475$.

- Los Deportes. (15 de junio de 1898, p. 288) 
- Los Deportes, (15 de julio de 1898, p. 323).

- Mora, C. (1970). Un hombre que vivió para el deporte, La Vanguardia Española, 3 de febrero, 25

- Polea. (1912). El XXV aniversario de la Sociedad Gimnástica Española, Gran Vida, $n .^{\circ}$ 106, 73.

- Rivero, A. (2003). Deporte y Modernización, Consejería de Cultura y Deportes, -Dirección General de Deporte- Comunidad de Madrid.

- Rivero, A. y Sánchez R. (2011) The British Influence in the Birth of Spanish SportInternational Journal of the History of Sport, Sept, Vol. 28, $\mathrm{N}^{\circ} 13,2011,1788-1809$. https://doi.org/10.1080/09523367.2011.594686

- Rivero, A. (2012). Semblanza: La Real Sociedad Gimnástica Española, Revista Internacional de Ciencias del Deporte, International of Sport Science, RICYDE, Vol. VIII, Año VIII, n. ${ }^{\circ} 29$, Julio, 272-273.

- Salazar, Bernardo de, (2000) Gimnástica y Racing, dos clubes madrileños, Cuadernos de Fútbol, n. ${ }^{\circ}$ 9, 22-36

- Sevilla, P (1951). Medio siglo de la Real Sociedad Gimnástica Española (1887-1937), Madrid, Silverio Aguirre, Impresor.

- Swing, (1919).Luchas grecorromanas, Heraldo Deportivo, n. ${ }^{\circ}$ 149, 258-259.

- Tello, J. (1998). Documento, Asociación de Estudios Históricos del Deporte.

- Torrebadella-Flix, X., Olivera-Betrán, J., \& M-Bou, M. (2015). Origen e institucionalización de las asociaciones gimásticas y deportivas en el siglo XIX en España, (1822-1900). Apunts. Educación Física y Deportes, 119, 7-54. https://doi.org/10.5672/apunts.2014-0983.es.(2015/1).119.01

- Torrebadella-Flix, X. (2015). Forjando los Juegos Olímpicos de Barcelona: La contribución de Narciso Masferrer y Sala en la configuración del deporte nacional e internacional (19001910). Citius, Altius, Fortius, 8(1), 61-104.

- Un gran festival Gimnástico, (1918), Gran Vida, n. ${ }^{\circ}$ 178, 101 